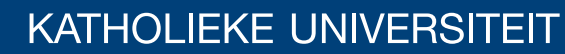 \\ LEUVEN
}

\section{Faculty of Business and Economics}

3LRGXFWWHOKFHM WAP VI

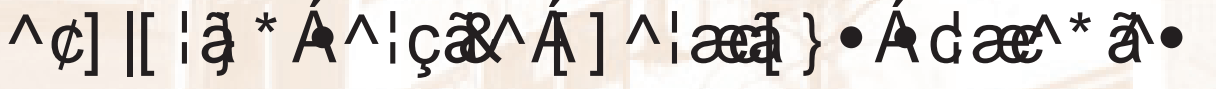

3 HMAN\& ROQQDQGO DUI/ DP EUHFKW

DEPARTMENT OF DECISION SCIENCES AND INFORMATION MANAGEMENT (KBI) 


\title{
Product service systems: exploring service operations strategies
}

\author{
Pieter Colen ${ }^{1}$, Marc Lambrecht ${ }^{2}$ \\ ${ }^{1}$ Research Center for Operations Management, Faculty of Business and Economics, K.U.Leuven, Leuven, Belgium \\ (corresponding author: pieter.colen@econ.kuleuven.be) \\ ${ }^{2}$ Research Center for Operations Management, Faculty of Business and Economics, K.U.Leuven, Leuven, Belgium
}

\begin{abstract}
Purpose - The purpose of this paper is to shed light on the operational principles that can be applied when offering integrated solutions of both products and services, i.e. product-service systems (PSS). Manufacturing companies that start pursuing a service oriented strategy face many new challenges. We investigate which well-known operational principles can be of merit to these companies and how these principles can be put to action.

Design/methodology/approach - The paper reports on the main findings of a structured return on invested capital (ROIC) analysis. We cascaded the ROIC metric into a limited set of core operational drivers. We then identified operational practices which could be applied to improve the ROIC by influencing the operational drivers. The operational practices were distillated from a close collaboration with a manufacturing company that pursues a product-service strategy.

Findings - Five generic strategic guidelines are formulated and translated into a wide range of operational practices.

Research limitations/implications - The paper provides a range of operational practices in the PSS business. Many of these practices are based on well-known operational principles but still need further elaboration with respect to the interrelationships between products and services.

Practical implications - The five service operations strategies can guide practitioners in their quest for operational excellence in the field of PSS.

Originality/value - Our main contribution is that we prove the usefulness of generic operational principles and translate them into clear guidelines to be applied for companies offering product-service systems.

Keywords - Operations management, Product service systems, Incentives, Service operations strategies

Paper type - Research paper
\end{abstract}

\section{Introduction}

Stagnating demand, high labor costs, demanding legislation and throat cutting competition have become part of life for many manufacturers in developed countries. These phenomena have unleashed a relentless search for ever increasing productivity. As a result, productivity has soared but employment rates have declined and the expected profits did not materialize or did not last (Wise and Baumgartner, 1999). Confronted with this harsh reality, many manufacturers are now in distress.

Nevertheless, some original equipment manufacturers (OEMs) have escaped the downward trend in employment and company value. Although these manufacturers are a diverse lot, ranging from defense 
contractors to home appliance manufacturers, they all have in common that they dared to look outside their traditional manufacturing business. By doing so, they have discovered the profit potential of services and have moved downstream in the supply chain. This profit potential has shifted their strategies away from selling products towards a more integrated strategy of value co-creation together with the customer.

Over the years the installed base of sold equipment has grown steadily, outnumbering product sales in almost any industry. The installed base of automobiles outnumbers new sales with a ratio of 13 to one while for airplanes this ratio runs up to 150 planes in use per new sale (Wise and Baumgartner, 1999). Customers spend considerable amounts of cash and effort to equipment already bought. If the offering is right, customers are willing to hand-over at least some of the after sales activities, which opens the door for new profit sources for the OEM. With such a potential market it is not surprising that serving the installed base is turning out to be big business (Cohen et al.,2006b).

Increasing numbers of manufacturers are recognizing the profit potential of services. Cisco Systems (Cohen et al., 2006b), GE (Johnstone and Wilkinson, 2009), Xerox (Baines et al., 2007) and Rolls-Royce (Baines et al., 2007) are just a few of the well-known examples of manufacturers that have successfully made the strategic decision to offer integrated solutions of both products and services. These integrated solutions are known as product service systems (PSS) and enhance the product offering with services to increase the total value proposition.

Advocates of service oriented strategies point to strategic, economic and environmental benefits of pursuing a service oriented strategy. Services are attractive because they are characterized by high margins, stable revenues and high quality service will promote new equipment sales (Wise and Baumgartner,1999; Visnjic and Van Looy, 2009). From a strategic perspective, services can establish a close and long-term relationship with customers, which at the same time locks-out competitors. Moreover integrated solutions are less easy to copy, making them a lasting source for differentiation (Oliva and Kallenberg, 2003). From the literature it seems almost undeniable that servicing the installed base is indeed a profit boon for manufacturers.

It is because they are fueled by this business sense that PSS are a promising vehicle for environmental sustainability. Product service systems are a market compatible way of reshaping the manufacturer's strategy towards more sustainability. A lot of authors and authorities, including the UN, believe that the offering of PSS will launch considerable savings in material and energy consumption (Baines et al., 2007; Pawar et al., 2009). When OEMs take over after sales activities, they become responsible for such things as waste disposal, component replacement and energy use. With the right contractual incentives, OEMs will incorporate after sales resource use in their decision making, effectively reducing the environmental impact during the entire life cycle of the equipment. The development of PSS will help companies comply with and even surpass increasing environmental obligations. In practice we observe the launch of energy saving services, refurbishment and recycling activities and efforts to increase the reliability of equipment.

The incentive structure is an important element in the development of product service systems. Without the additional offering of services, a sales transaction also leads to a hand-over of responsibilities from the OEM to the customer. After the sale, the customer becomes the bearer of all costs involved with the use and disposal of the equipment. Although customers will take the total cost of ownership into account when making purchasing decisions, it is only when the manufacturer is actively involved in after sale service that true compatibility of incentives occurs. Within the OEM organization, the management responsible for services will act to reduce the total cost of servicing the equipment. Because of the prolonged responsibility of the OEM, both the customer and the manufacturer will thrive to lower the costs over the total life of the equipment. If the OEM succeeds in reducing the total cost of servicing 
below the do-it-yourself costs of the customer, value is created by delivering these services. We will call this increased value the "service gain" (Figure 1). The creation of a service gain is crucial for the success of the PSS, as only then a win-win situation becomes possible. A customer who can reduce his total cost of ownership by purchasing services, will do so, while the manufacturer will offer services as long as they are profitable. Beside these service profits, the manufacturer will reap additional benefits as mentioned above.

Figure 1. Representation of cost throughout the lifecycle, with the service gain as benefit of the PSS

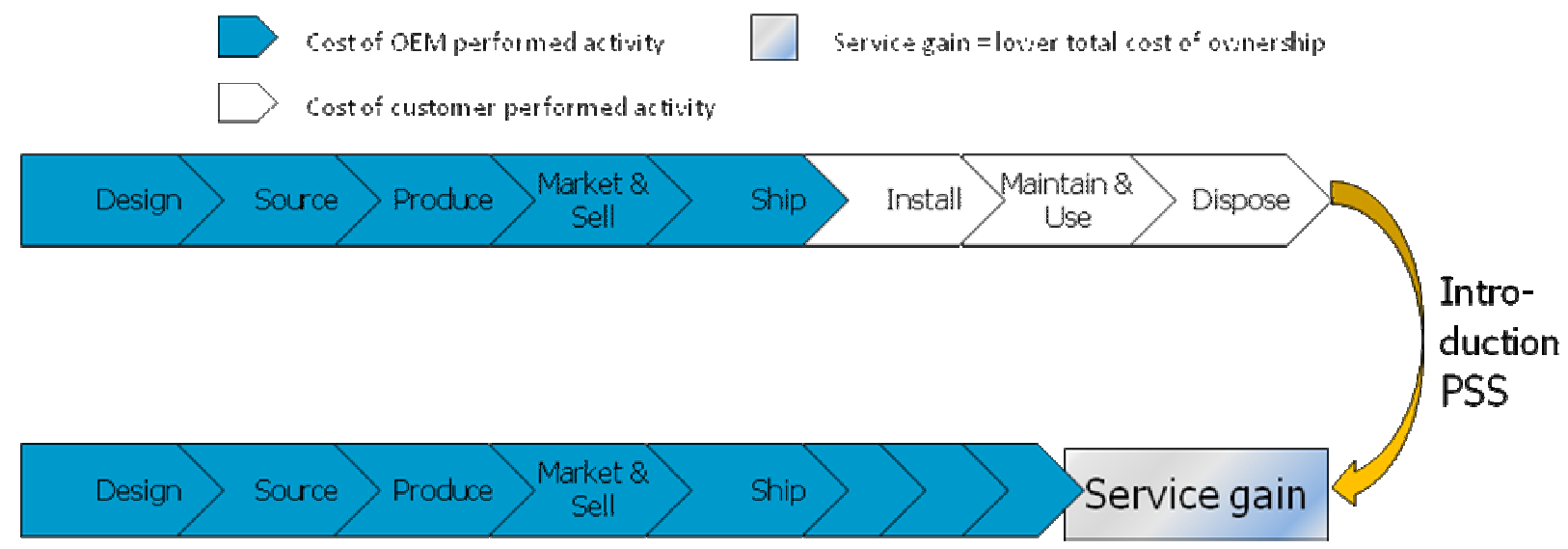

As manufacturing firms are expanding their operations into services, the fundamental task that awaits them is to create a service gain, i.e. the OEM has to achieve lower total cost of ownership than the customer can realize himself. This task mandates effective and efficient service supply chains in which materials, labor and information are orchestrated to serve the needs of the customer.

The research reported in this paper is the result of a collaboration between the authors and a large OEM in the compressed air, generators and mining industry. We started with a full deployment of the return on invested capital in services. Next, we broke down the financial metrics into its key operational ingredients resulting in a list of "service performance parameters" (performance drivers). Examples of these performance parameters include: number of stocking locations, number of spare part sku, variability of spare part demand, efficiency of field engineers, utilization rate of field engineers, traveling distances, number of service vans, ... Finally, we distillated five service operations strategies effecting the performance parameters and translated them into operational practices (Figure 2). The numbers in figure 2 were disguised, so they do not represent the situation of the OEM. In this paper we focus on these service operations strategies as a paradigm for successfully managing service operations. The service operations strategies are presented in section 2. We conclude in section 3 . 
Figure 2. The five operations strategies
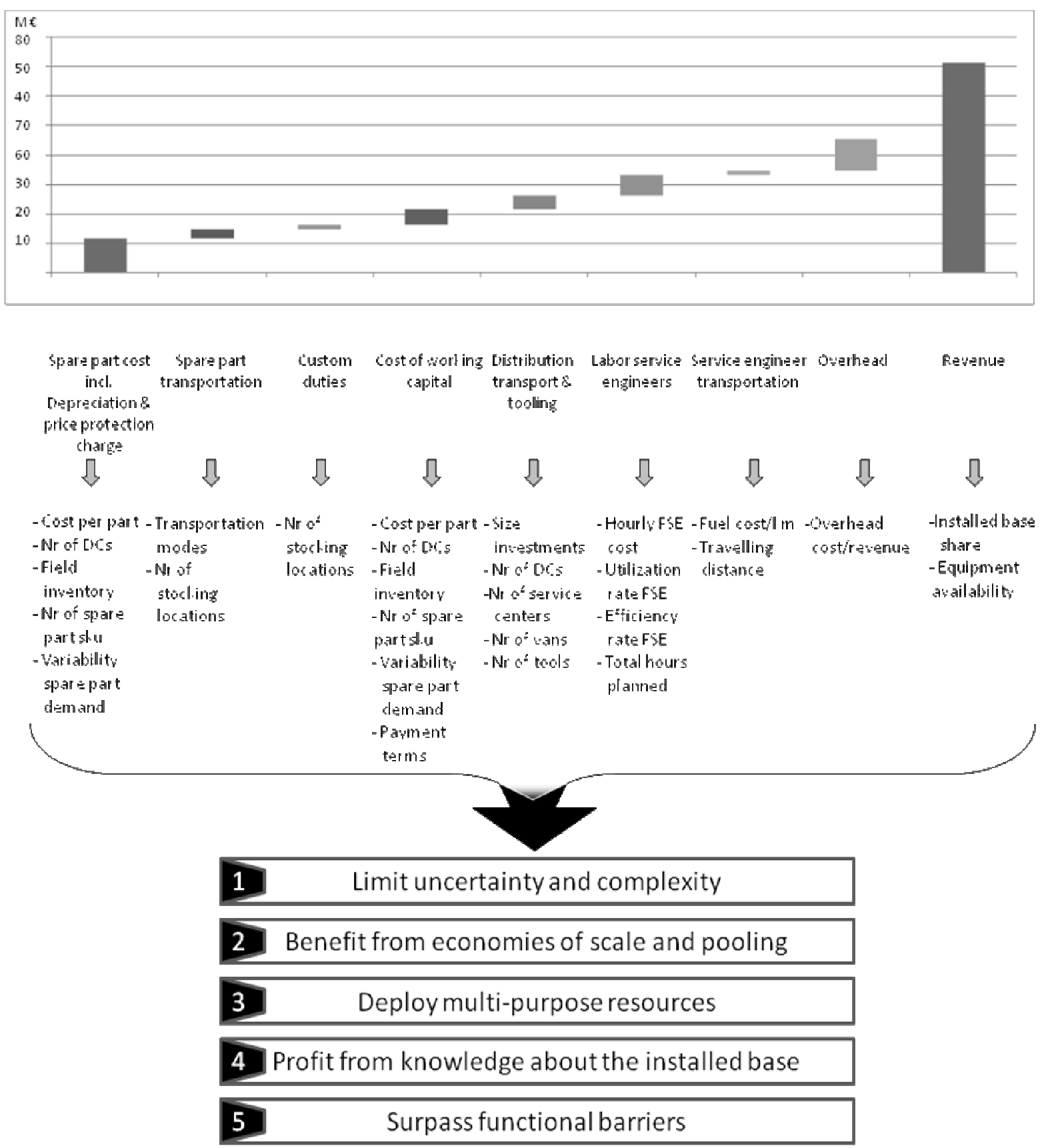

\section{Service operations strategies}

The possibility to augment profitability while at the same time become more sustainable, makes PSS an appealing development for manufacturing companies. But to succeed in the service industry, the manufacturing firm will have to take many new hurdles. We have formulated five service operations strategies that can guide the OEM while setting up a service supply chain. We emphasize the importance of limiting the uncertainty and complexity while developing services and service operations. Secondly, 
the OEM has the opportunity to outshine local service providers by benefiting from scale and pooling effects. To be able to respond swiftly to service requests across the globe, the deployment of multipurpose resources is a non-negligible strategic option. Our fourth strategy advocates the use of installed base data to make the unpredictable predictable. Lastly, the OEM should be aware that to succeed in PSS, functional barriers should be surpassed, not least between the manufacturing and service business. In the following subsections, the strategies will be explained more thoroughly and translated into more practical actions.

\subsection{Limit uncertainty and complexity}

With characteristics such as customer co-production, highly variable servicing times and no inventory of finished goods, service operations are generally thought of as more uncertain than manufacturing operations. Moreover the impact of decisions is especially long in a service environment (Wilkinson et al., 2009). Indeed, service contracts often tend to have a duration of several years and today's manufactured equipment will have to be supported during many years to come. This prolonged impact of current decisions amplifies the detrimental effects of uncertainty and complexity, but at the same time it can be an opportunity for the OEM. By carefully designing the service products and the equipment being sold, the manufacturer can effectively gain control over his service operations and avoid a lot of problems such as peaks in workload or high variability in spare part demand. Our first service operations strategy, emphasizes the importance of mitigating uncertainty and complexity when designing PSS.

\subsubsection{Move from reactive to scheduled service}

A first way to limit uncertainty and complexity in services is to move from reactive to scheduled (proactive) service. An important element of uncertainty in service operations is timing: when do we need to perform service? Is it the customer or the service provider who makes the timing decision? Service can be delivered whenever the customer wants (service-on-request), when agreed upon with the customer (service-on-appointment) or based on a schedule (service-by-schedule). By offering planned services, either service-on-appointment or service-by-schedule rather than service-on-request, the OEM can get away from daily-fire fighting and start streamlining his operations. For example, in maintenance services, the service provider can decide to promote preventive maintenance instead of repair services, preventive maintenance has the advantage of being highly predictable and easier to schedule.

In addition, there is a trade-off to be considered between the frequency and content of the service sessions and the risk of emergency service needs. For example, performing preventive maintenance more frequently and more thoroughly will diminish the risk of emergency repairs. A very well-known example of this practice is the maintenance notification you get after having driven $\mathrm{x} \mathrm{km}$ with your car. This is how the manufacturer tells you to make a maintenance appointment at your car dealer. Of course you can chose to ignore the notification, taking the risk of an unexpected car breakdown, probably at a time that your car is indispensable. It is clear that sometimes it is better to invest in more frequent and more extended service than ending up with high costs of emergency service and opportunity costs of the failure. To minimize the expected total cost of performing maintenance service, models can be employed. Maintenance models characterize the impact of different kinds of service interventions on the failure probability of the equipment (Bartholomew-Biggs et al., 2009; Doyen and Gaudoin, 2004). Carefully analyzing when, how often and what to do in each service session limits the risk of unexpected failures for the owner of the equipment but also limits the uncertainty in the demand for service as experienced by the manufacturer of the equipment. That is why a smart design of service contracts turns a chaotic, unstructured service office into a well organized and planned business, delivering trouble-free operations at a low cost. Making your business less reactive and more proactive can indeed lower costs because of e.g. improved capacity scheduling and less emergency shipments. 


\subsubsection{Bundle and standardize services}

In manufacturing it is a well-known fact that offering a wide range of products and options induces complexity costs such as higher design, inventory and quality costs (Yunes et al., 2007). Just the same as in manufacturing, service offerings need to be tailored to the needs of customers while maintaining low costs. The use of standard modules that can be configured as needed, is an elegant way to deal with this seemingly impossible trade-off between standardization and customization. When making the trade-off, two possible approaches exist. Either you offer pre-selected product bundles or you have a standard service which the customer can customize with add-ons selected from a choice menu. Both approaches aim at reducing the number of potential "service configurations". No matter which approach is chosen, devising an offering which appeals to customers and reduces complexity is challenging. Luckily the literature gives some guidance: both high level strategic road-maps (Ramdas, 2003) and detailed mathematical methodologies (Fogliatto and da Silveira, 2008) have been developed. Bundling and choice menu strategies clear the way for standardization of procedures and processes but at the same time impose a need to say: "No, we do not do that." to some customers.

\subsubsection{Take on more responsibility}

As we made clear before, the need to create a service gain calls for efficient operations. When trying to increase efficiency, the OEM is restricted in his efforts due to the high level of customer involvedness in service operations. It is the customer who decides upon access to his premises, which services may be performed and maybe even dictates which employee of the OEM is allowed to perform the service. Imagine for example how difficult it is to optimize maintenance operations if you do not control the inventory of spare parts. If the OEM can create a service gain by taking-over activities of the customer such as spare part inventory management, the manufacturer should do so. By taking on more responsibilities the service provider gains control over his service operations and can create a larger service gain. As both parties should benefit from this gain, customers will agree upon higher levels of information sharing and hand over more and more tasks, leading the way to increased benefits for both manufacturer and customer.

In industries where the equipment is complex and the opportunity costs of breakdowns are severe, OEMs are increasingly taking full responsibility for the performance of the PSS. These service contracts are known as performance based contracts. Typically the payments under a performance based contract will be calculated based on the up-time or the actual use of the equipment. The best known example are the schemes in the aerospace industry where the airline company pays a fee per flying hour to the manufacturer of the engine. By linking the payment to the actual value generated by the equipment, i.e. flying hours, performance based contracting aligns the incentives between the OEM and the customer (Guajardo et al., 2009). If the customers does not benefit from the equipment because it does not work, the OEM will neither benefit. Under performance based contracting, the OEM has total control of all the support activities and can manage them according to his own preferences (Kim et al., 2007). It is the OEM who decides when to perform maintenance, when to preventively replace a part or even when to replace the entire machine. The OEM receives total control of equipment support while the customer gets peace of mind and strong guarantees on service performance. The increased control lowers the uncertainty in the service operations by making them less dependent on the customer. Moreover performance based contracts incorporate a payment scheme that is no longer linked to time or material used. With such an incentive structure the OEM reaps the benefits of developing equipment that lasts longer and is easier to serve. Now both the OEM and the customer have the same goal, i.e. lower total cost of ownership. The higher level of control and the alignment of incentives between customers and 
manufacturer, make us belief that performance based contracting will lead to the creation of a higher service gain compared to contracts with less responsibilities.

By taking on more responsibilities the OEM can reduce the uncertainty in his service operations. The lower operational uncertainty is however countered by the higher financial risks of having more responsibilities. The risk shift towards the manufacturer does not necessarily result in a higher service gain. Sometimes the customer will be better equipped to take on the service risk. The issue of correctly allocating the risk is a delicate balancing act. It is therefore advisable to carefully design a portfolio of service products. Figure 3 illustrates the concept of a service portfolio. The OEM takes on more responsibilities as he moves from spare part sales to performance based contracting. It is postulated that the larger the portfolio the higher the service profit potential becomes. Almost all OEMs will sell spare parts, which is a fairly low risk activity. Some OEMs will enhance their offering by providing the personnel to perform the service. This will lead to the commonly used time and material contracts in which the customer pays for the time and material used to perform the service. More advanced service providers will start to offer services for a predetermined fixed price, sometimes covering multiple years of service. The most advanced OEMs will start combining product and services in one contract, even with performance based guarantees and payment schemes. Finally some OEMs even go as far as optimizing the operations of the customer. It is important to note that although the OEM will evolve towards more advanced service products, the simple products still have a role to play. The OEM will have to manage a portfolio of different service products. Therefore thorough knowledge of the different contract types and their risk profile is needed in order to price these service products according to their risk and value for the customer. If properly managed and priced, the more advanced service products should have a higher profitability. This higher profit potential is based on the larger service gain resulting from higher levels of control and alignment of incentives.

Figure 3. Representation of the service portfolio

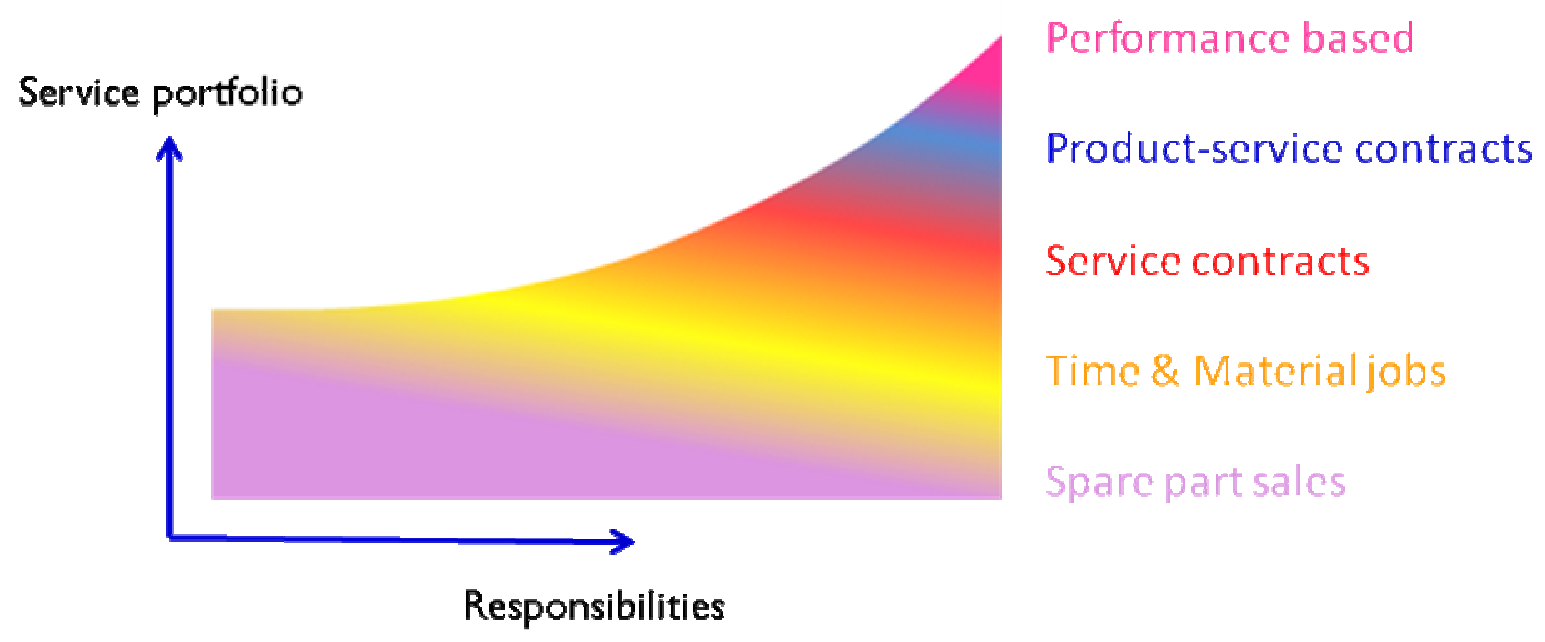

\subsubsection{Adapt end-product design}

The uncertainty and complexity that surrounds after sales services are highly influenced by the design of the equipment. By taking service requirements into account when developing new equipment, the OEM can make life easier for his own service operations. Design-for-service falls apart in two objectives: reliability and maintainability. The objective of reliability is concerned with developing equipment that 
has a low failure rate by using redundancy in components and more extensive engineering efforts (Hussain and Murthy, 2003). Maintainability however focuses on the ease and costs of providing the necessary support services. Although the level in which service issues are taken into account during the design of equipment varies greatly between companies, leading manufacturers are showing the way. Exemplary practices identified are the use of a formal process to ensure that service related goals are met, the early involvement of maintenance experts and the use of quantitative analysis and lifetime models (Goffin and New, 2001). In practice maintainability can be improved by a modular design and commonality in parts, resulting in savings in stocking levels (Kranenburg and Van Houtum, 2007; Thomas and Warsing, 2007).

The OEM can avoid problems such as peaks in workload or high variability in spare part demand by looking at the design of the equipment and services being sold. A thought-through design translates itself to efficient operations and to a larger service gain.

\subsection{Benefit from economies of scale and pooling}

A successful pursuit of a service-oriented strategy mandates a service supply chain that is responsive and efficient. The OEM will have to maximize his scale and take advantage of pooling while not losing sight of the local needs of customers. Centralization, customer \& service territory pooling and grouping of service tasks are the major actions to take within our second service operations strategy. Scale and the ability to pool risk is a key advantage for the OEM compared to the usual low scale service if performed by the customer. If the OEM does not use this advantage, the ability to create a service gain is at risk.

\subsubsection{Centralize the spare part supply chain}

The spare part supply chain is in many ways more challenging than a manufacturing end product supply chain. The reasons being: the existence of a complicated multi-echelon structure, the presence of a high number of skus, the need to serve a highly geographically dispersed installed base and the flows of both repairables and consumables. The goal of the spare part supply chain is to deliver the right parts to the right place within an agreed-upon time frame at the lowest possible cost. The trade-off between responsiveness and efficiency can be made by conscientiously selecting the geographic stocking location of the spare part (centralized or decentralized) and the position of the spare part in the product hierarchy (individual component, module, sub-assembly or end product) (Cohen et al., 2006a). If downtime is extremely expensive such as in the semi-conductor industry, storing a back-up machine at the customer site may be optimal. When the customer does not care that much about the up-time of his machine and is very cost sensitive, then the best way to serve him is probably by shipping the specific failed part from a central warehouse. The existence of two interrelated hierarchies makes the spare part supply chain both rich and challenging.

Consider spare part supply chain without repair facilities. In this case, the centralization of inventory is a well-known practice to obtain efficiency gains (Teo et al., 2001). Of course any savings from centralization of inventory will be countered by increased transportation costs and longer delivery times. The trade-off between inventory consolidation and transportation costs has given rise to the locationinventory problem in which both facility location and inventory management are combined (Erlebacher and Meller, 2000).

Repair or refurbishment of used parts is a distinguishing characteristic of many spare part supply chains. Repair and refurbishment facilities can be modeled as queuing systems. It follows from queuing theory that pooling servers lowers lead-times (Hopp and Spearman, 2000). Moreover centralized repair facilities face lower overhead costs than decentralized facilities do. The centralization of repair capacity 
will however effect the inventory and transportation costs. Where to locate the repair facilities, how much inventory of repairable units to carry and how much capacity to acquire for each facility are strongly intertwined issues and should be solved simultaneously (Rappold and Van Roo, 2009).

\subsubsection{Pool customers \& service territories}

In a service environment, customers are often allocated to a specific service engineer (a technician of the OEM) or each service engineer has his own service territory for which he is responsible. Workload balancing over time is one of the key objectives when assigning customers to service engineers or when determining service territories (Blakeley, 2003). Services are by nature intangible and can not be stored, therefore there is an instantaneous link between demand and workload. Did you ever try to make an appointment to let your car tires change on a Saturday? Then probably you had to wait for three weeks or the technician convinced you to come on a Thursday. This is a classical example of how variability in demand deteriorates the service experience. The service provider can however safeguard his service levels by pooling customers or service territories. Effectively pooling demand smoothens the workload, making reliable customer service a contract winning characteristic.

By pooling customers with negatively correlated demand, the server will experience a balanced workload throughout the year. The same workload balancing can be obtained by pooling the service territories of different service engineers. The service engineers as a group will then experience a lower level of variability in demand. Xerox is one of the companies that has transformed its service territories from single server islands to larger collaborative service territories, in effect pooling the demand across territories (Watson et al., 1998). Reduction of response times and capacity levels are the rewards for the OEM that takes up the challenge of balancing workload (Hopp and Spearman, 2000).

\subsubsection{Group service tasks}

Lowering the total costs of ownership, i.e. creating a service gain, is not a one-day-job. Typically the service oriented manufacturer will serve his customers on a regular basis. For example a machine needs oil changing after 2000 running hours and calibration every 1500 hours. After 1500 running hours the service engineer will travel to the customer's site and start performing the service. Which service task will the engineer perform? Only calibration or both calibration and oil changing? In the latter solution the two service tasks are grouped together into one service encounter, saving time and money on set-up activities such as traveling, but increasing cost due to the high frequency of oil changing. Taking into account setup costs when designing and scheduling service tasks, can yield considerable efficiency gains (Budai et al., 2006).

Whether centralizing inventory and capacity, balancing workload or grouping service tasks, the goal is to reduce overall costs both for the OEM as for the service customers. For the former the benefit is higher profit margins, for the latter the total cost of ownership tumbles. So economies of scale and risk pooling turn-out well for both parties, that is as long as nothing unplanned happens (indicating the importance of the first strategy). When an unplanned situation occurs, such as a machine failure the customer will demand immediate action as the machine down-time may shoot his ownership costs through the roof. In emergencies like these the OEM has to be responsive: having spare parts and service engineers nearby and willing to add service visits for a single service task. In such circumstances being flexible is the only way to be responsive without throwing overboard all the benefits from centralization and pooling. 


\subsection{Deploy multi-purpose resources}

The equipment sold by an OEM often performs a mission-critical task in the operations of the customer and therefore any equipment disruption has to be solved as quickly as possible. The negative impact of equipment downtime can be minimized by having back-up equipment at the customer site but this solution is prohibitive expensive in most settings. In many service environments companies find themselves in a situation where they need to be flexible to become both responsive and efficient. Therefore we state that an OEM should consider deploying multi-purpose resources to increase his flexibility. Although they are more expensive, multi-purpose resources allow for a swift reaction in case of emergency without deploying excess resources. We will discuss flexibility actions related to inventory, capacity and the service policy. Multi-purpose resources give the OEM the capability to react swiftly to emergencies without having to deploy excessive resources.

\subsubsection{Be smart with inventory}

Flexibility in the use of inventory can be obtained by implementing transshipments. Transshipments are shipments of parts between two stocking locations at the same echelon of the supply chain. Saturn for example uses transshipments between its dealers (Cohen et al., 2000). If an unfortunate dealer faces a stock-out of a spare part, a transshipment from a nearby dealer quickly resolves the problem. Thanks to the flexible usage, the inventory is shared among several retailers, in effect lowering the total amount of inventory needed for the high speed service provided (also known as virtual pooling). Kranenburg and van Houtum (2009) use real-life data from an OEM in the semi-conductor industry to prove that by allowing just a few well-chosen distribution centers to perform transshipments the cost savings can already be substantial. Besides transshipments, the OEM can choose to use emergency shipments, which are a more straightforward approach to increase responsiveness while enjoying pooling benefits (Wong et al., 2006).

Spare parts can also be flexible by their characteristics, meaning that they can be used for multiple demand types. The best example of this is a commonality part which can be used to satisfy the demand originating from different machine types. When a stock-out of a specific part occurs, the OEM may find it optimal to deliver a substitute part that works as well or even better than the original configuration (upgrading). Savings in emergency shipments, reordering and stock-out costs justify the use of substitute parts that are more expensive than the original ones.

An OEM that promotes flexibility in inventory is able to enjoy risk pooling effects while locating inventory closer to the customer. With spare parts nearby, finding people to perform the service becomes key.

\subsubsection{Create a flexible workforce}

As the implementation of a service oriented strategy goes beyond selling spare parts, the OEM needs trained workers to execute the services being sold. Ideally a service engineer should be available whenever and wherever a service request appears. This may be an unreachable goal, but leading service organizations are taking up the challenge by enhancing the flexibility of their workforce. Flexibility for workers refers to issues such as the level of cross-training and the use of flexible working hours.

Cross-trained service engineers are able to execute a multitude of service tasks. With such a workforce the OEM aspires to have a properly trained service engineer available for each emergency. Service engineers will come across a wide range of different job types ranging from simple oil changing to complex problem solving and upgrading of equipment. Even the equipment itself is a diverse lot with 
different technologies and configurations. For most OEMs, it is probably unthinkable of having service engineers capable of performing all possible service tasks on all types of machines. As cross-training improves flexibility but increases costs, determining how much cross-training should be appropriate is an important question. The literature is quite clear about this: although cross-training drastically lowers labor requirements, only a small amount of cross-training is sufficient to realize most of the advantages of full cross-training (Wallace and Whitt, 2005), there is even evidence of this rule in a field service context (Agnihothri et al., 2003). The dependency of the optimal level of cross training on the amount of proactive vs. reactive services performed (section 2.1.1.) is studied by Colen and Lambrecht (2010). Successfully deploying competence differentiated technicians is dependent on the integration of the service engineer skill levels in an intelligent routing tool (Agnihothri and Mishra, 2004).

Letting the available capacity fluctuate with demand is especially useful in a service context and can be achieved e.g. by overtime, flexible lunchtimes or temporal personnel (Hopp and Van Oyen, 2004).

\subsubsection{Adapt service policy based on field data}

Most often the execution of services involves making an appointment with the customer or committing to a response time after which his service request must be handled. When making such an arrangements the customer will expect conformance with the promises made. Flexible service policies are service policies in which the service provider makes promises to customers based on real time data. Such a use of field data improves conformance with customer expectations, responsiveness and/or efficiency. Quotation of response times, setting of time windows and determining when to execute a next service task, are all activities were the service provider can benefit from up-to-date data (Apte et al., 2007, Cui and Li, 2006).

\subsubsection{Be fast when it counts}

What matters for customer-centric service is not being fast, but being fast when it counts. Without proper priority rules that dictate when to go in overdrive, service managers may lose control and end up with delivering fast service to customers that do not pay for it (Caggiano et al., 2007). After enabling high responsiveness, the OEM has to set out rules determining for which customers and/or in which situations to unleash its high responsiveness.

Service jobs, certainly in maintenance service, greatly differ in their level of urgency. They range from simple inspections to high emergency repairs. Even within the class of repairs divergence exist, as a failed equipment can be a small leisure airplane or a 250 million \$ worth passenger aircraft. Making a distinction in the execution of different jobs adapts the service to customer needs and willingness to pay. Moreover a differentiated service offering, creates the opportunity to price discriminate between customers (Pangburn and Stavrulaki, 2008). So the goal is to deploy scarce resources for maximal value creation. Revenue management techniques can be applied here.

In order to maximize the service gain, the priority rules should not be limited to the order in which service jobs are handled. One can prioritize the handling of a certain service job but without the proper materials all the efforts are in vain. So besides service jobs, spare part investment and allocation should be prioritized.

To deliver the highest value with limited inventory, leading companies determine which and how much spare parts to stock based on cost-benefit ratios (Cohen et al., 2006a; Gorman and Ahire, 2006). The cost element is the cost of carrying the part while the benefit should be expressed by using customeroriented measures such as customer waiting time, order fill rate or spare part criticality. Service can be improved without putting more money in inventory, if the OEM stocks more of the spare parts that matter 
most for the customer and less of the extreme expensive or irrelevant parts (Caggiano et al., 2007). Another approach to avert running out of spare parts for those customers that value the parts the most, is reserving inventory. When reserving inventory, the OEM sets a threshold inventory level below which only high priority demand is fulfilled from stock while other customers have to wait until replenishment (Cohen et al., 2006b).

In this subsection we have seen that efficiency is no silver bullet for success in services. Due to the high costs of machine breakdowns, service providers have to act swiftly in the case of an emergency. However to safeguard efficiency, the service operations have to be flexible and the high responsiveness should only be used when necessary. This dynamic use of responsiveness calls for an OEM that is aware of the service environment by using data related to the installed base.

\subsection{Profit from knowledge about the installed base}

The reduction of uncertainty and complexity are crucial in after market activities. Therefore the smart OEM will gather information about the installed base to make the unpredictable predictable. With this intelligence the OEM can outshine competitors and deepen the relationship with his customers. The installed base constitutes a rich compilation of data about the customer, the equipment and the service history. This data can be cultivated to intelligence based on disciplines such as diagnostics, reliability analysis and forecasting. Storing and distributing this information is a significant challenge (Främling et $a l, 2006)$ but being able to proactively react is a bountiful capability.

\subsubsection{Diagnose}

With the maturity of internet enabled remote sensing technology, the manufacturer can gather vast amounts of data about the operations and conditions of the equipment built. But even scrutinizing more readily available information such as service history and warranty data can clear the mist around important operational questions. What is the likely cause of a breakdown? Which spare parts are most likely needed for a certain service job? Answering these questions requires the use of data mining and statistical techniques (Jeong et al., 2007).

Moreover, intelligence about the use of the equipment and the services being sold, is precious information for the product design and marketing department. With the power of knowledge the OEM can launch new products that are tailored to the customer needs and offer information services that share the intelligence with the customer.

\subsubsection{Perform reliability analysis}

Knowing how often equipment fails is fundamental information for the design and pricing of maintenance service contracts. Besides this information reliability analysis can also provide insight into the effect of maintenance actions on the probability of failure (Doyen and Gaudoin, 2004). Intelligence about the risks of equipment failures helps the OEM determine the service requirements of equipment. As the installed base grows, the OEM will now have the capability to proactively recruit and train employees to cope with the future (predicted) workload.

\subsubsection{Forecast demand}

Besides service capacity the OEM also needs sufficient spare parts. The demand for certain spare parts can be intermittent, i.e. characterized by a long periods of very low demand, interrupted with demand 
peaks, making forecasting for spare parts especially difficult. The conventional way to forecast spare part demand is to use historical sales data (Teunter and Duncan, 2009) but there is a growing body of researchers that considers spare part demand as dependent. The spare part demand is indeed dependent on factors such as the size of the installed base or the failure rate of the equipment (Hong et al., 2008). With reliable forecasts, the OEM can anticipate future spare part needs by adapting his inventory allocation and procurement practices accordingly.

Intelligence based on installed base data helps the OEM optimize his service operations. Moreover based on the installed base knowledge the OEM can make well-founded decisions concerning the pursuit of other strategies related to marketing, design, service portfolio etc.

\subsection{Surpass functional barriers}

As product service systems are integrated solutions of equipment and service, the equipment and service design is influenced by one another with a focus on a common goal, i.e. customer value (Johnstone and Wilkinson, 2009). Many authors have noted that the creation of an independent service organization with its own profit and loss responsibility is a cornerstone for success in services (Oliva and Kallenberg, 2003). We adhere to this conclusion and advocate the creation of a separated (i.e. separated from the product divisions) service organization acting as a business unit. The service management will then give service business the attention it needs to flourish. Keeping the service activities within the product divisions may prohibit economies of scale. Unfortunately the creation of a independent service organization can be seen as a threat by the manufacturing units. Both divisions, manufacturing and service, can chose to optimize their own profitability with disregard of corporate interests. As we will explain, the alignment of decisions becomes crucial.

Is the core manufacturing business willing to increase production cost in order to lower servicing cost? Does the service division deliver high quality service leading to new equipment sales? What is the optimal mix between manufacturing and servicing profitability? These are fundamental issues demanding an approach that surpasses functional barriers. It is important to keep in mind that the incentives of the manufacturing and service division can differ. The balancing act between manufacturing and service interests, can be guided by the ambition to deliver the functionality the customer requires against the lowest total cost of ownership. As lower total costs should induce maximal corporate profits, reducing the total cost of ownership is a worthy common goal. Setting a common goal helps to surpass the functional barriers and increase corporate value. To make the common goal acceptable for all parties involved, a quantitative model can be constructed to calculate the total costs of ownership (Cohen et al., 1997). Such a quantitative model can help senior management setting the entire organization on the same rails towards the common destination of PSS value.

\section{Conclusion}

The emerging strategy of original equipment manufacturers to focus more on aftermarket service activities is a very promising strategy to avoid the commodity trap. The homogenization of products and production methods has led to throat cutting competition and in many cases to thin margins. The evolution towards product service systems is a business model innovation targeting a service gain for both the manufacturer and the customer. The service gain is equivalent to the lower total cost of ownership over the entire lifetime of the equipment.

However, the implementation of a PSS business model is a very difficult endeavor. In this paper we report on the major conclusions from a close collaboration between the authors and an OEM that has embarked on a mission to implement product service systems. We formulate five service operations 
strategies that can guide the manufacturer towards profitable PSS. The first strategy deals with limiting the uncertainty and complexity in service operations. Second, scale and pooling effects should be realized. The deployment of multi-purpose resources constitutes the third operations strategy. Next we advocate the use of installed base data to make the unpredictable predictable. Lastly, the OEM should be aware that in order to succeed in PSS functional barriers should be surpassed, not least between the manufacturing and service business. In this paper we cascade each of these strategies into its key operational ingredients. In this way we offer the reader a whole set of operational practices to turn his after sales services into a real profit generating engine.

\section{References}

Agnihothri, S.R., Mishra, A.K. and Simmons D.E. (2003), "Workforce cross-training decisions in field service systems with two job types.", Journal of the Operational Research Society, Vol. 54 No. 4, pp. 410-418.

Aghnihothri, S.R., Mishra, A.K. (2004), "Cross-training decisions in field services with three job types and server-job mismatch.", Decision Sciences, Vol. 35 No. 2, pp 239-257.

Apte, A., Apte, U.M. and Venugopal, N. (2007), "Focusing on customer time in field service: A normative approach.", Production and Operations Management, Vol. 16 No. 2, pp 189-202.

Baines, T.S., Lightfoot, H.W., Evans, S., Neely, A., Greenough, R., Peppard, J., Roy, R., Shehab, E., Braganza, A., Tiwari, A., Alcock, J.R., Angus, J.P., Bastl, M., Cousens, A., Irving, P., Johnson, M., Kingston, J., Lockett, H., Martinez, V., Michele, P., Tranfield, D., Walton, I.M., Wilson, H. (2007), "State-of-the-art in product-service systems", Proceedings of the Institution of Mechanical Engineers Part B - Journal of Engineering Manufacture, Vol. 221 No. 10, pp.1543-52.

Bartholomew-Biggs, M., Zuo, M.J. and Li X.H. (2009), "Modeling and optimizing sequential imperfect preventive maintenance.”, Reliability Engineering \& System Safety, Vol. 94 No. 1, pp 53-62.

Blakeley, F., Bozkaya, B., Cao, B.Y., Hall, W. and Knolmajer, J. (2003), "Optimizing periodic maintenance operations for Schindler elevator corporation.”, Interfaces, Vol. 33 No. 1, pp 67-79.

Budai, G., Huisman, D. and Dekker, R. (2006), "Scheduling preventive railway maintenance activities.", Journal of the Operational Research Society, Vol. 57 No. 9, pp 1035-1044.

Caggiano, K.E., Jackson, P.L., Muckstadt, J.A. and Rappold, J.A. (2007), “Optimizing service parts inventory in a multiechelon, multi-item supply chain with time-based customer service-level agreements.", Operations Research, Vol. 55 No. 2, pp 303-318.

Cohen, M.A., Agrawal, N. and Agrawal, V. (2006a), "Achieving breakthrough service delivery through dynamic asset deployment strategies.", Interfaces, Vol. 36 No. 3, pp 259-271.

Cohen, M.A., Agrawal, N. and Agrawal, v. (2006b), "Winning in the aftermarket.", Harvard Business Review, Vol. 84 No. 5, pp 129-138.

Cohen, M.A., Cull, C., Lee, H.L. and Willen, D. (2000), "Saturn's supply-chain innovation: High value in after-sales service.", Sloan Management Review, Vol. 41 No. 4, pp 93-102.

Cohen, M.A. and Whang, S.J. (1997), "Competing in product and service: A product life-cycle model.", Management Science. Vol. 43 No. 4, pp 535-545.

Colen, P. and Lambrecht, M. (2010), "Cross training policies in a maintenance field service organization.”, Working paper, K.U.Leuven, Leuven.

Cui, L. and Li, H. (2006), "Opportunistic maintenance for multi-component shock models", Mathematical Methods of Operations Research, Vol. 63 No. 3, pp 493-511.

Doyen, L. and Gaudoin, O. (2004), "Classes of imperfect repair models based on reduction of failure intensity or virtual age.”, Reliability Engineering \& System Safety, Vol. 84 No. 1, pp 45-56. 
Erlebacher, S.J. and Meller, R.D. (2000), "The interaction of location and inventory in designing distribution systems.", Iie Transactions, Vol. 32 No. 2, pp 155-166.

Fogliatto, F.S. and da Silveira, G.J.C. (2008), "Mass customization: A method for market segmentation and choice menu design.", International Journal of Production Economics, Vol. 111 No. 2, pp 606622.

Främling, K., Ala-Risku, T., Karkainen, M. and Holmstorm, J. (2006), “Agent-based model for managing composite product information.”, Computers in Industry, Vol. 57 No. 1, pp 72-81.

Goffin, K. and New, C. (2001), "Customer support and new product development - an exploratory study.", International Journal of Operations \& Production Management, Vol. 21 No. 3, pp 275-301.

Gorman, M.F. and Ahire, S. (2006), "A major appliance manufacturer rethinks its inventory policies for service vehicles.”, Interfaces, Vol. 36 No. 5, pp 407-419.

Guajardo, J.A., Cohen, M.A. and Netessine, S. (2009), "Impact of performance-based contracting on product reliability: An empirical analysis.", Working Paper, The Wharton school, Pennsylvania, 022010.

Hong, J.S., Koo, H.Y., Lee, C.S. and Ahn, J. (2008), "Forecasting service parts demand for a discontinued product.", Iie Transactions, Vol. 40 No. 7, pp 640-649.

Hopp, W. and Spearman, M. (2000), Factory Physics, Irwin/McGraw-Hill, New York.

Hopp, W.J. and Van Oyen, M.P. (2004), "Agile workforce evaluation: a framework for cross-training and coordination.", Iie Transactions, Vol. 36 No. 10, pp 919-940.

Hussain, A. and Murthy, D.N.P. (2003), "Warranty and optimal reliability improvement through product development.", Mathematical and Computer Modeling, Vol. 38 No. 11-13, pp 1211-1217.

Jeong, I.J., Leon, V.J. and Villalobos, J.R. (2007), "Integrated decision-support system for diagnosis, maintenance planning, and scheduling of manufacturing systems.", International Journal of Production Research, Vol. 45 No. 2, pp 267-285.

Johnstone, S., Dainty, A. and Wilkinson, A. (2009), "Integrating products and services through life: an aerospace experience.", International Journal of Operations \& Production Management, Vol. 29 No. 5, pp 520-538.

Kim, S.H., Cohen, M.A. and Netessine S. (2007), "Performance contracting in after-sales service supply chains.", Management Science, Vol. 53 No. 12, pp 1843-1858.

Kranenburg, A.A. and van Houtum, G.J. (2007), "Effect of commonality on spare parts provisioning costs for capital goods.", International Journal of Production Economics, Vol. 108 No. 1-2, pp 221-227.

Kranenburg, A.A. and van Houtum, G.J. (2009), "A new partial pooling structure for spare parts networks.", European Journal of Operational Research, Vol. 199 No. 3, pp 908-921.

Oliva, R. and Kallenberg, R. (2003), "Managing the transition from products to services.", International Journal of Service Industry Management, Vol. 14 No. 2, pp 160-172.

Pangburn, M.S. and Stavrulaki, E. (2008), "Capacity and price setting for dispersed, time-sensitive customer segments.", European Journal of Operational Research, Vol. 184 No. 3, pp 1100-1121.

Pawar, K.S., Beltagui, A. and Riedel, J. (2009), "The pso triangle: designing product, service and organization to create value.", International Journal of Operations \& Production Management, Vol. 29 No. 5, pp 468-493.

Ramdas, K. (2003), "Managing product variety: an integrative review and research directions.", Production and Operations Management, Vol. 12 No. 1, pp 79-101.

Rappold, J.A. and Van Roo, B.D. (2009), "Designing multi-echelon service parts networks with finite repair capacity.”, European Journal of Operational Research, Vol. 199 No. 3, pp 781-792.

Teo, C.P., Ou, J.H. and Goh, M. (2001), "Impact on inventory costs with consolidation of distribution centers", Iie Transactions, Vol. 33 No. 2, pp 99-110.

Teunter, R.H. and Duncan, L. (2009), "Forecasting intermittent demand: a comparative study.", Journal of the Operational Society, Vol. 60 No. 3, pp 321-329.

Thomas, D.J. and Warsing, D.P. (2007), "A periodic inventory model for stocking modular components.", Production and Operations Management, Vol. 16 No. 3, pp 343-359. 
Visnjic, I and Van Looy, B. (2009), "Manufacturing firms diversifying into services: A conceptual and empirical assessment.", Working paper, K.U.Leuven, Leuven.

Wallace, R.B. and Whitt, W. (2005), "A staffing algorithm for call centers with skill-based routing.", Manufacturing\& Service operations Management, Vol. 7 No. 4, pp 276-294.

Watson, E.F., Chawda, P.P., McCarthy, B., Drevna, M.J. and Sadowski, R.P. (1998), "A simulation metamodel for response-time planning.", Decision Sciences, Vol. 29 No. 1, pp 217-241.

Wilkinson, A., Dainty, A., Neely, A. (2009), "Changing times and changing timescales: the servitization of manufacturing.", International Journal of Operations \& Production Management, Vol. 29 No. 5, pp 425-430.

Wise, R. and Baumgartner, P. (1999), "Go downstream: The new profit imperative in manufacturing.", Harvard Business Review, Vol. 77 No. 1, pp 133-142.

Wong, H., van Houtum, G.J., Cattrysse, D. and Van Oudheusden, D. (2006), "Multi-item spare parts systems with lateral transshipments and waiting time constraints.", European Journal of Operational Research, Vol. 171 No. 3, pp 1071-1093.

Yunes, T.H., Napolitano, D., Scheller-Wolf, A. and Tayur, S. (2007), "Building efficient product portfolios at John Deere and company”, Operations Research, Vol. 55 No. 4, pp 615-629. 